ISNN 1810-5491

Instituto de Estudios Nacionales

Cuadernos Nacionales

$\mathrm{N}^{\circ} 28$, enero-junio, 2021

\title{
La brisa bolivariana y su efecto en América Latina
}

\author{
Arturo Rene Dávila Mera ${ }^{1}$ \\ Universidad Internacional de Seguridad (España) \\ arturodavilamera62gmail.com
}

\section{Resumen}

Los riesgos y amenazas actuales, presentan una imbricada trama de aristas diferentes que emergen incomodando los "statu quo" tradicionales, sacándolos de su zona de confort y obligándolos a desenvolver sus actividades en entornos caóticos, que los impulsan por supervivencia a la iniciativa y a la creatividad, so pena de implosionar ante la presión del entorno. La dinámica de los eventos suscitados en los últimos años, dejan entrever la presencia de otro tipo de amenazas, fuera de toda norma y que se unen y desunen vertiginosamente desafiando las diferentes doctrinas y generando el requerimiento urgente de definirlas desde su percepción, su escritura, su instrumentalización y su ideologización para poder visualizarlas y enfrentarlas, dándose a conocer como amenazas híbridas, por los diferentes elementos evidenciados en diferentes conflictos y latitudes distintas pero con características aplicables y extrapolables a problemáticas similares en la región, tal como la denominada "brisa bolivariana" de finales de 2019.

Palabras clave: Amenazas híbridas, socialismo del siglo XXI, seguridad, doctrinas, postmoderno
Abstract
1. Director Académico Universidad internacional de seguridad UNIVERIS (España) y coordinador para América Latina. 
The current risks and threats, present an imbricated plot of different edges that emerge disturbing the traditional "status quo", taking them out of their comfort zone and forcing them to carry out their activities in chaordic environments, which drive them for survival to initiative and creativity, under pain of imploding under the pressure of the environment. The dynamics of the events that have arisen in recent years, hint at the presence of other types of threats, out of all norms and that unite and break vertiginously, challenging the different doctrines and generating the urgent requirement to define them from their perception, their writing, their instrumentalization and ideologization to be able to visualize and confront them, making themselves known as hybrid threats, due to the different elements evidenced in different conflicts and different latitudes but with characteristics applicable and extrapolated to similar problems in the region, such as the so-called "Bolivarian breeze" end of 2019

Keywords: Hybrid threats, 21st century socialism, international security, doctrines, postmodern

\section{Motivación}

A finales de 2019 empiezan a manifestarse movilizaciones sociales de protesta contra los regímenes democráticos de países de América Latina, en los que las elecciones populares colocaron en el poder, a gobernantes considerados como "de oposición” para los gobiernos alineados con el "socialismo del siglo XXI"; lo llamativo de esta situación, fueron los niveles inusitados de violencia y vandalismo que acompañaron a dichas movilizaciones, rebasando incluso a la acción de las fuerzas del orden y provocando severos daños en la propiedad privada y pública que trajeron graves consecuencias a la economía y pusieron en cuestionamiento a la gobernabilidad de los mismos atentando contra la estabilidad democrática y los derechos humanos.

Idea que se desea probar

La pretensión de imponer un nuevo orden ideológico o teoría de relaciones internacionales en la región, a cualquier precio

Desarrollo

Si nos enfocamos desde el punto de partida de los diferentes paradigmas de las relaciones internacionales, podríamos ubicar el presente fenómeno dentro de la corriente 
Marxista, en su versión modernizada bajo el membrete de socialismo del siglo XXI, amparado en el marco del neoestructuralismo, corriente que se autodefine de esta manera: "Lejos de ser un conjunto de ideas auto contenidas el (neo)estructuralismo es un sistema abierto que se presta a establecer diálogos con otras tradiciones de pensamiento en economía, como las corrientes heterodoxas. Estas últimas incluyen un conjunto heterogéneo de enfoques que incluyen a los evolucionistas e institucionalistas, la escuela de la regulación, los marxistas y radicales, y los post-Keynesianos. Durante muchos años, estas tradiciones nos han permitido alimentar un análisis crítico del pensamiento y las políticas económicas” (Barcena A, Prado A 2015). Además, la metodología con la que procura implantarse dentro del sistema internacional, se enfoca dentro de la configuración de las amenazas híbridas.

El fenómeno se encuentra en desarrollo y ha convulsionado a varios países de América Latina, pretendiendo implantarse por cualquier medio, lícito o no a fin de concretar "nuevos" enfoques ideológicos y económicos de conducción e interrelación de los estados, pretendiendo alcanzar o imponer un enfoque regional.

Ante esta situación se debe tener en cuenta hasta qué punto este expansionismo ideológico afecta a la soberanía y poder de los Estados en su contraposición con el enfoque realista o neorrealista de cada estado en el que interviene, así como su influencia en el conglomerado infiltrando sus ideas fuerza en el constructivismo propio de los grupos culturales que se encuentran dentro de los Estados plurinacionales y que pueden ser utilizados para materializar fuerzas de choque que bajo estas ideas, pretendan imponerlas por la fuerza o captar el poder mediante la insurgencia

Claro está que esta explosión violenta que raya en la insurgencia en la región, no ha sido espontánea ni aislada, sino que obedece a un proceso de panificación y ejecución bien planeado y ejecutado con anterioridad y con claros visos de incubación y proyección prospectiva de los escenarios que progresivamente se han ido presentando. Si bien los paradigmas de seguridad internacional han variado y evolucionado con el acontecimiento de hechos históricos tales como la caída del muro de Berlín y la desintegración de la URSS 
apareciendo sus versiones recicladas como neo tendencias y luego convertidas en post neo tendencias, los tiempos históricos también han convulsionado los parámetros convenidos sobre lo que es normal y lo que no, tornándose en postnormales y así en las respectivas disciplinas al referirse a esta temporalidad tales como la inteligencia postnormal

Las condiciones en cuanto esta temporalidad han cambiado profundamente como la intensificación del dinamismo de las interrelaciones de la sociedad que presenta diferentes características con relación a la modernidad pudiendo determinarse un nuevo período denominado postmodernidad. Por su parte, Bauman califica a la sociedad actual como una "sociedad líquida", metaforizando a la sociedad actual argumentando que no existen "pautas estables ni predeterminadas en esta versión privatizada de la modernidad" y que su narrativa gira en torno a cinco elementos básicos alrededor de los cuales se ha modificado la condición humana: emancipación, individualidad, tiempo/espacio, trabajo y comunidad (Bauman, Z 2000).

Las características del comportamiento humano en esta época de cambios, procurando su emancipación, se caracteriza por un exceso de libertad que ha dejado sin norte a la eterna conquista de los principales conflictos de la humanidad, que casi siempre buscaban la "libertad de", la "libertad para" y la "libertad de sí mismo" (Llano,A 1999) , sin embargo con el aparecimiento de comportamientos postnormales hacen que las principales teorías de relaciones internacionales empiecen a convulsionar, apareciendo teorías por temática, tales como la teoría del feminismo, teoría de género, teorías verdes, construcción de teorías propias de la seguridad en post guerra fría, (González 2019), escuela de Copenhage caracterizada por la teoría de la securitización, todas de las teorías postguerra fría que procuran abordar temas específicos y teorías parciales que resultan insuficientes ante la complejidad de esta sociedad postmoderna, siendo la más aproximada en la búsqueda de soluciones totales la teoría de sistemas.

Desde este enfoque, se puede decir que las relaciones internacionales deberían abordar la teorización pretendiendo encontrar una explicación a la totalidad de la problemática de manera omnicomprensiva, "no podemos señalar que las Relaciones 
Internacionales sean un área del conocimiento abocada a un sector de la realidad exclusivo en absoluto. Muy por el contrario, al abordar un aspecto de la realidad social, debe, de manera impostergable, recurrir a los avances de otras disciplinas de las ciencias sociales; de ahí su carácter interdisciplinario. Es decir, al ser las Relaciones Internacionales una ciencia más de este campo, debe recurrir a las formulaciones y disquisiciones de áreas afines como el Derecho, la Economía, la Ciencia Política y la Sociología, entre otras, todas las cuales son interdisciplinarias en la medida que se retroalimentan continuamente para su avance, revisando de manera crítica y constante el de las demás" (González, A 2017) y dentro de las teorías sociales la que más se aproxima puede ser la teoría de la complejidad, continúa expresando que "la disciplina de las relaciones internacionales se ha venido constituyendo como un área de conocimiento sumamente amplia, pues su objetivo de aprehender la realidad de manera integral y omnicomprensiva, exige de un esfuerzo de integración y síntesis de las aportaciones desarrolladas en diversas áreas del conocimiento. Es en virtud de esta situación que la interdisciplinariedad, la multidisciplinariedad y la transdisciplinariedad, han sido desde su inicio, sus características esenciales". La apuesta ulterior de unir a la complejidad con las características de la transdisciplinariedad ha dado lugar a la transcomplejidad que puede ser una herramienta investigativa que más se ajusta a las relaciones internacionales.

Desde este enfoque, (Tello 2010) plantea las relaciones internacionales como una interdisciplina integradora de diferentes áreas del conocimiento, que aportan a su conocimiento. Por su parte (Angarita-Calle 2008) plantea las relaciones internacionales como un vasto y complejo campo de estudio de las diferentes esferas de las relaciones entre las naciones basadas en las políticas frente a los otros Estados, de carácter institucional y público, pero también particular y/o privado. "Decidir por un abordaje transcomplejo involucra a todas las etapas de la investigación; permite responder en diferentes planos, así como presentar la información en diferentes niveles. Asimismo, requiere profundización sobre la realidad que se indaga, ámbitos con los que se vincula y procesos sociales que involucra. De este modo se obtienen conocimientos y saberes más significativos" (Villegas C 2006) 
De este modo, el problema en cuestión del presente trabajo, no solo afecta las esferas de un solo país con la imposición forzada de un gobierno que pauperiza a su pueblo desviando sus riquezas de un modo autoritario y violento, sino que genera condiciones de vida extremadamente difíciles para el conglomerado, que al no sentirse representado por esta forma de dictadura democrática, emprende un éxodo inverso al tradicional, es decir en vez de buscar como objetivo países desarrollados como EEUU, en su desesperación enfilan a países en vías de desarrollo pero con condiciones de sustentabilidad social mejores que el suyo, aunque los tradicionalistas opinen que emigrar entre países subdesarrollados equivalga a cambiar de camarote en el titanic.

\section{Los prolegómenos de la fiebre del pasado futuro cercano}

En julio de 1990, se funda el llamado Foro de Sao Paulo que procuraba reunir esfuerzos de los partidos y movimientos de izquierda y de ultraizquierda para debatir sobre el escenario internacional luego de la caída del muro de Berlín y las consecuencias del neoliberalismo en los países de América Latina y el Caribe, la opinión internacional no le prestó mayor atención bajo el argumento de que el socialismo y el comunismo habían demostrado históricamente su incapacidad de convertirse en un modelo exitoso, ya que para entonces el único integrante que ejercía el poder era Cuba; hasta 1998 en que la elección de Hugo Chávez en Venezuela inscribe la llegada al poder de un gobierno de izquierda y miembro de dicho Foro, después de muchas décadas en América Latina, seguido en 2002 por Luis Inacio Lula da Silva en Brasil, 2004 Tabaré Vásquez en Uruguay, 2004 Evo Morales en Bolivia; 2005 y 2013 Michelle Bachelet en Chile, 2006 Rafael Correa en Ecuador y Daniel Ortega en Nicaragua; 2008 José Mujica en Uruguay, 2009 Mauricio Funes en El Salvador y Dilma Rousseff en Brasil; 2010 Ollanta Humala en Perú, 2011 Nicolás Maduro en Venezuela, 2014 Salvador Sánchez y 2018 Andrés López Obrador en México.

La corriente socialista alcanza el poder y procura perennizarlo mediante medios lícitos e ilícitos, y con la ejecución de una planificación detallada que incluía la legalización de lo ilegítimo mediante cambios constitucionales que bajo el pretexto de favorecer a los 
indefensos pone sobre sí misma a la declaración de los derechos humanos, y terminan favoreciendo a los delincuentes, facilitando el flujo de las teorías temáticas tales como las feministas, de género, etc., debilitando paralelamente la capacidad de empleo de la fuerza legítima del Estado, mediante la fuerza pública cuya intervención en conflictos de orden interno califica de lesa humanidad el empleo de sus armas para repeler la violencia del conglomerado, mientras que a este le da el carácter de delito común si hiere o mata a un policía, carabinero o militar; y por otro lado, la captación del poder tanto de los órganos de poder internos de los Estados cuanto con la creación de nuevos órganos de poder tales como el electoral y el de participación ciudadana, así como nuevas estructuras de inteligencia a favor del gobierno de turno y que trastocan la estructura de los aparatos de inteligencia tradicionales debilitándolos y tornándolos ineficaces, lo cual les garantizaba la permanencia en el poder mediante mecanismos de "democracia" espurios, pero legales. De este modo se acomoda a sus intereses absolutistas aquello de que "las bases más importantes de todo Estado se encuentran en las buenas leyes y las buenas armas" (Maquiavelo, N 1513).

La proyección de la permanencia de esta ideología reciclada se procura conseguir mediante la educación; de este modo los textos escolares impartidos por el gobierno "revolucionario", están plagados de propaganda política y de principios de carácter socialista que pretenden no solo adoctrinar a los niños y adolescentes, sino paralelamente impregnar en su imaginario la figura heroica del gobernante poniéndolo a la par de los próceres más descollantes de la historia de cada país, abonando la "lucha de clases" y el odio hacia aquello que represente la empresa privada y la opulencia (que finalmente terminan financiando mediante actos de corrupción los lujos del mandatario y su equipo cercano, así como de su movimiento político).

Mientras que a nivel universitario de grado y postgrado, se le da protagonismo con soporte gubernamental, a la corriente neoestructuralista como alternativa económica innovadora que es presentada como la panacea para sacar al país y a la región de la opresión, el subdesarrollo y la dependencia de la oligarquía y el imperialismo, con claros mensajes ideológicos transversales, asegurando su permanencia generacional, mientras 
sobre endeudan al país y comprometen por adelantado los recursos del estado, dejando a sus posibles relevos situaciones económicas difícilmente superables para el erario nacional que causarían la necesidad de adopción de medidas correctivas que repercutirían en la popularidad de sus gobiernos, creando el clima necesario para los levantamientos populares y la insurgencia, de una población subsidiada con bonos que acostumbran a la población a no tener que trabajar para ganarse su sustento, dependiente de un Estado paternalista y obeso que mediante estas medidas procura popularidad y longevidad de su mandato por la vía electoral (clientelismo)

Mientras tanto, las relaciones internacionales en este período continúan sosteniendo como mejor alternativa para su ejecución el paradigma del neoliberalismo, que considera la prevalencia de la comunidad internacional y que la seguridad internacional es un bien común que permite que los estados pueden trabajar juntos con la ayuda de las instituciones internacionales para la promoción de los intereses comunes; mientras que tanto China cuanto Rusia ya habían logrado establecer una "cabeza de playa" en Venezuela y mantienen distraído e EEUU de esta intromisión hemisférica mediante mecanismos comerciales que ponen en jaque al gobierno norteamericano, reforzando la idea del Foro de sao Paulo de imponer como fin último el paradigma Marxista bajo la denominación de neoestructuralismo en la región, permeando incluso organismos supranacionales como la Corte Interamericana de Derechos Humanos, la OEA y la ONU a la cual postulan subrepticiamente a integrantes de dicho Foro como autoridades, alterando la seguridad hemisférica. Quizás por ello cobra vigencia el afirmar que la globalización avanza hacia el pasado, (Henriquez 1995)

Paralelamente dentro del comportamiento social postmoderno se observa un trastrocamiento de los valores fundamentales cooperativos propios del contrato social, pasando al protagonismo del individualismo traducido en un anacoretismo digital, dónde el entorno inmediato deja de existir en aras del mundo individual y personal, en una sociedad en que el exceso de libertad es tan grande que asusta, ya que la libertad exige paralelamente responsabilidades que el postmoderno tiene miedo de asumir, por ello el encanto de la creación de nuevas entidades estatales que asumen las decisiones que debería tomar el 
conglomerado y los liberan así de responsabilidades, dejándoles vía libre para la imposición ideológica, la corrupción y su gula de poder.

De otro lado, el paradigma neorrealista o estructuralista en el ámbito postmoderno deja en evidencia que la teoría de Waltz (1988), al describir que el equilibrio ideal de los estados se encuentra en la bipolaridad, de algún modo vuelve a cobrar vigencia, (Waltz, K 1988) ante la influencia de Rusia en el Continente americano como soporte de la dictadura venezolana, regresando al pasado como decíamos al inicio, pues cualquier cambio empírico del sistema puede traer resultados repentinos en los casos particulares, y algunos nuevos cambios en todo el sistema de relaciones internacionales, pueden hacer relevantes de nuevo las teorías estructuralistas de Waltz, como suele ocurrir con las teorías científicas.

Por su parte Mearsheimer considera que "los EE.UU. son la hegemonía regional que es amenazada por China, que se está convirtiendo en hegemonía regional también" (Mearsheimer, J 2001), e incluso ha hecho presencia y se ha manifestado en apoyo al régimen venezolano, y que será capaz de competir con los EE.UU. en la región del Pacífico por lo menos. Predice la futura colisión entre China y los Estados Unidos.

Ambos autores coinciden en que la hegemonía norteamericana no puede ser exclusiva y de manera indirecta coinciden en que pueden presentarse otras hegemonías en la región que pueden alterar el orden internacional, como se está evidenciando en el análisis en desarrollo de este documento.

Considerando la opinión al respecto de Krasner distingue en sus teorías un concepto como el de "Estado débil" que, en su opinión, es el factor de inestabilidad y amenaza para los "Estados poderosos". El "Estado débil" es incapaz de asegurar la aplicación de las leyes en su territorio, y eso crea condiciones favorables para que aparezcan los centros del terrorismo internacional. Krasner supone que para evitar esto los "Estados débiles" deben estar bajo el control de los "Estados fuertes", que tienen la hegemonía mundial y regional. El hecho de que el Estado sea débil es suficiente para interferir en sus asuntos internos. Esta idea se desarrolla en su teoría de la "soberanía gradual", en la creencia de que no todos los Estados nominalmente soberanos deben considerarse como plenamente soberanos. "Los 
verdaderos Estados soberanos existen sólo en los Estados desarrollados democráticos occidentales" (Krasner, 2005).

En el concepto, Krasner estudió los regímenes del Tercer Mundo, demostrando que los liberales en las relaciones internacionales tienen la tendencia equivocada, en su opinión, de observarlos desde la ayuda económica y el apoyo técnico a su desarrollo, cuando, según Krasner, al igual que otros Estados tienen como objetivo el poder y la seguridad. Al recibir el apoyo de Occidente tratan de convertir éste en poder potencial. En algunos casos, esto puede provocar nuevos conflictos y amenazas para el propio mundo occidental, como podría asimilarse en el caso venezolano.

Ante estos escenarios la seguridad regional se torna incierta, mientras que la alteración de las condiciones normales de gobernabilidad ha sido cambiada, afectando a la libertad de acción para la toma de decisiones al interior de los Estados, limitando su capacidad de reacción en cuanto a la seguridad y orden interno, tornándose impredecible y débil, siendo susceptibles a que graves alteraciones al orden público puedan afectar seriamente su gobernabilidad y capacidad de reacción tornándose vulnerables ante la imposición de condiciones que pretendan ser impuestas por la fuerza, dejando en entredicho la autoridad y autonomía de los gobiernos de turno con graves afectaciones a la economía y a la convivencia social.

\section{Materialización de amenazas híbridas en la brisa Bolivariana postnormal}

Los inicios del siglo XXI se han caracterizado por el desarrollo de amenazas de carácter transnacional, por agentes no estatales, que ponen en cuestión los límites tradicionales entre la seguridad exterior y la seguridad interior, al tiempo que crece la conciencia de la estrecha interrelación entre los problemas económicos, sociales y medioambientales y los problemas de seguridad. Es así que, en la Declaración sobre Seguridad en Las Américas, 28 de octubre 2003 México, se plantea el surgimiento y presencia de "nuevas amenazas" en el siguiente orden: 
- “1. AMENAZAS "DURAS” a la seguridad: terrorismo, delincuencia organizada trasnacional, narcotráfico, corrupción, lavado de dinero, tráfico ilícito de armas;

- 2. AMENAZAS DE ORIGEN SOCIAL CON IMPACTO EN LA SEGURIDAD: la pobreza;

- 3. AMENAZAS PROVENIENTES DE LA NATURALEZA Y LA SALUD: desastres naturales, deterioro del medio ambiente y Sida;

- 4 AMENAZAS CONTRA LA INTEGRIDAD DE LAS PERSONAS, originadas por causas sociales, pero realizadas por grupos de crimen organizado: la trata de personas

- 5. AMENAZAS ON LINE: delitos cibernéticos;

- 6. AMENAZAS PROVENIENTES DEL TRANSPORTE DE PRODUCTOS PELIGROSOS, desechos tóxicos, petróleo y material radioactivo;

- 7. LA AMENAZA POR LA POSIBLE POSESIÓN DE ARMAS DE DESTRUCCIÓN MASIVA por personas o grupos terroristas que puedan actuar en el hemisferio". (O.E.A. 2003)

Como se puede observar, la tradicional distinción entre los dos ámbitos de la seguridad, el exterior y el interior, está perdiendo relevancia, cuestionando principios como la rígida diferenciación entre las misiones de las fuerzas armadas y de las fuerzas de seguridad, pues el proceso de globalización está potenciando las amenazas transnacionales, es decir las amenazas a la seguridad interior procedentes de agentes no estatales que actúan a través de las fronteras internacionales.

Un estudio del Strategie Studies Institute de los Estados Unidos, publicado poco antes del 11-S, destacaba ya cómo este tipo de amenazas, especialmente el terrorismo internacional, los ataques cibernéticos a las infraestructuras nacionales y la delincuencia organizada transnacional, plantean la necesidad de combinar las estrategias respectivas de 
las instituciones de defensa y las de justicia e interior, aunque ello no resulta en absoluto fácil, sobre todo porque es necesario evitar que resulte dañado el fundamental equilibrio entre libertad y seguridad

La conceptualización de estas "nuevas" amenazas, como amenazas híbridas posteriormente, parten de los llamados conflictos asimétricos, caracterizados por una desigualdad abismales entre adversarios con capacidades desiguales que procuran equilibrarse con el empleo de técnicas, tácticas y procedimientos clandestinos, furtivos e insidiosos e incluso contrarios a las leyes y usos de la guerra, como fue el caso del conflicto de Afganistan en el cual este pequeño país puso en jaque a la OTAN, a partir de allí, entran en juego no solo los elementos tradicionales de los conflictos armados sino que entran en juego una serie de factores que deberán ser considerados caracterizando los denominados “conflictos híbridos", de este modo se define como tales a la "intencionada mezcolanza de elementos asimétricos y convencionales. La hibridez es en esencia ambigua e intencionalmente equívoca, en este tipo de escenarios casi todo vale y los actores se mueven en la penumbra de la denominada zona gris. Los estados participan "sin participar", promueven y apoyan las diferentes facciones, pero de un modo soterrado tratando de eludir posibles RESPONSABILIDADES, se confunden y funden combates militares, atentados terroristas, intervenciones policiales, propaganda, desinformación, manipulación, actuaciones en el ciberespacio, etc.” (Matter y Hoffman 2005)

Sin embargo la hibridez no solo está presente en los conflictos sino también y con mayor frecuencia en las nuevas amenazas que se convierten en amenazas híbridas, que se desenvuelven en escenarios con extrema complejidad, notable ambigüedad y sobresaliente incertidumbre; se aprovecha de su naturaleza y dinámica propias con características eminentemente transnacionales; las amenazas hibridas dejan ya de configurarse como algo raro, volviéndose una manifestación típica de toda conflictividad transnacional, representando así el desafío contemporáneo de mayor presencia, incidencia y complejidad. El concepto se torna ambiguo, innovador, dinámico y flexible que va desde los actos violentos perpetrados por civiles militarizados filo-rusos al este de Ucrania hasta las 
masivas campañas de "fake news" y la manipulación de redes sociales durante el referéndum del Brexit.

En el ámbito social, las amenazas híbridas no necesariamente implican el uso de la fuerza o violencia, sino que pueden relacionarse con la utilización de múltiples elementos de poder, de sumisión e influencia, todos ellos relacionados con sectores no militares de la sociedad: áreas como la información, la política, la economía, las finanzas, los movimientos sociales, las infraestructuras críticas, las redes sociales, la cultura, el prestigio, el orden social. Todos ellos constituyen nuevos campos de acción, donde los actores del futuro buscarán desplegar sus estrategias y tácticas con el fin de ganar las diarias batallas que les permitan imponer su voluntad, mejorar su posición geopolítica y cumplir con su misión estratégica.

Las diferentes potencias militares mundiales, han establecido su propia doctrina de amenazas y guerra híbridas, por motivos del análisis que se pretende abordar en la región, nos referiremos a la denominada "doctrina china de la guerra sin restricciones", visión china sobre el desarrollo de los conflictos geopolíticos del futuro cada vez más tecnológico y multipolar. Esta doctrina propuesta representa un cambio radical en el concepto de la guerra a partir de la guerra del golfo (1990-1991), última guerra ganada en forma neta por EEUU.

Con la introducción de la tecnología, con la sumisión a la lógica del mercado y con las nuevas modalidades de combate, se modificó también el rol preponderante que la guerra tiene ahora de determinar quién detenta el poder e impone el orden en el escenario geopolítico mundial. La supremacía histórica de la capacidad militar (razón de fuerza) se ha quebrado.

En un mundo plagado de incertezas e interconexiones, las guerras sufren una metamorfosis compleja, dando lugar a "SEMIGUERRAS" o "CASI GUERRAS", allí donde la violencia militar se ha reducido, ha sido suplantada por violencias de tipo político, económico o tecnológico. Cambia así también el objetivo último de todo conflicto armado el cual pasa de ser "el uso de la fuerza para obligar a un enemigo que se someta a la propia 
voluntad" a un nuevo paradigma: "usar todos los medios, incluida la fuerza de las armas y los sistemas ofensivos militares y no militares, letales y no letales, para obligar al enemigo a aceptar nuestros propios intereses” (Qiao Liang y Wang Xiangsui 1999)

En vez de mantener una actitud previsible, convencional y estrictamente militar, esta doctrina propone vencer rápida y eficazmente a través de objetivos asimétricos (negar, destruir, desorganizar, desunir, denigrar y someter) dentro de la estructura organizativa y moral del adversario. Acciones que deberán ejecutarse dinámicamente y de manera proactiva, pensando fuera de los esquemas establecidos con una mentalidad avasalladora y triunfal (denunciar corrupción gubernamental del enemigo, reavivar viejas enemistades entre alianzas enemigas, poniendo a la población en contra de su gobierno o de otras poblaciones aliadas, burlarse de sus líderes o evidenciar la ineficiencia de sus instituciones, y muchas acciones más). Atacar a todos, de todas formas, en todo campo "es una cuestión de entender que siempre estamos decidiendo si ser el cazador o la presa".

La estrategia de la guerra sin límites, requiere una combinación estratégica de terrorismo, manipulación de los medios de comunicación, ataques a sitios web, manipulación del mercado bursátil para causar crisis financieras, difusión de virus informáticos y otras armas no convencionales: "una hermosa mañana la gente se despertará y descubrirá con sorpresa que algunas cosas gentiles y buenas han comenzado a adquirir características ofensivas y letales" (Li Cunshang 2008)

En agosto del 2015, El Presidente de Venezuela Nicolás Maduro, decretó el cierre de la frontera con Colombia. El motivo, según las autoridades, fue que tres militares venezolanos fueron atacados por supuestos paramilitares colombianos en dicha frontera. Este acontecimiento constituye uno de los múltiples que han sucedido y suceden en la frontera de alrededor de $2.200 \mathrm{Km}$, donde se han producido y producen conflictos de toda naturaleza.

Cuando empezaron los roces entre Venezuela y Colombia, ya Venezuela presentaba un nivel de inconformidad interna y de reclamos por parte de la población de su país por las precarias condiciones de vida existentes para la mayoría de la población, a pesar de ser uno 
de los países de Sudamérica con mayores recursos y riquezas naturales, pero con una administración deplorable que mantenía en condiciones de abundancia a su círculo más cercano y al alto mando militar, con ingentes contribuciones al gobierno cubano tanto en dinero, petróleo y otros bienes a cambio de asesoramiento socialista disimulado como ayuda médica, entrenamiento para las tropas y otros servicios de seguridad, mientras que ocultaba estas acciones bajo la fachada de solidaridad con el hermano pueblo cubano.

Este comportamiento anómalo y corrupto de administración pública degeneró en protestas callejeras que fueron permanente y violentamente sofocadas por el gobierno revolucionario de Maduro, generando miedo y desconfianza en la población, dando inicio a un éxodo en la región que hasta la presente fecha ha superado los cuatro millones de habitantes autoexiliados, en busca de mejores condiciones de vida. Sin embargo, se hace necesario tener presente que los procesos migratorios de esta naturaleza, son fácil blanco del tráfico de personas, narcotráfico, exportación de delincuencia e inclusive, que mezclados entre los migrantes se pueden mezclar agentes revolucionarios cuya misión sería sembrar e incubar la lucha revolucionaria socialista en diferentes países de la región.

Los roces entre Colombia y Venezuela se fueron intensificando hasta que el año 2015 sus diferencias subieron tanto de nivel que amenazaban con un posible conflicto armado ante la caída de un avión venezolano cuyo gobierno acusó a Colombia de haberlo derribado, habiéndose solicitado la mediación de los países de la región a fin de desescalar el conflicto. Las acusaciones de ambos lados siguieron presentándose con frecuencia y por diferentes temas, que si se había desalojado asentamientos colombianos en territorio venezolano, que si se había a cogido en territorio venezolano a integrantes de las FARC, que si Colombia introducía droga en territorio venezolano, que si Venezuela sobrepasaba el límite político internacional con sus tropas aduciendo ejercicios de campaña; en fin una larga lista de excusas y pretextos que mantenían en tensión la frontera colombo-venezolana y que servían de argumento para comprar armamento sofisticado a Rusia y China, mientras que Colombia conseguía ingresar a la OTAN bajo el apadrinamiento norteamericano. 
A mediados del 2019, las tropas venezolanas se movilizaron amenazantes hacia la frontera con Colombia, respaldadas por un discurso beligerante del gobernante venezolano, llegando a situaciones de casi guerra o no guerra, componente doctrinario de las amenazas híbridas.

Paralelamente apareció tanto por medios de difusión pública cuanto por las redes sociales, un video en el que los ex congresistas del reciente partido político FARC, anunciaban su retorno a la lucha armada; posteriormente las pericias realizadas al video dieron como resultado que fue realizado en territorio venezolano. Inteligencia colombiana así como elementos de la interpol pudieron verificar que integrantes de las FARC se encontraban residiendo en Venezuela y que su actividad estaría vinculada a la protección de integrantes del Foro de Sao Paulo que llegaban a Venezuela, así como al reclutamiento de personas que pretendían migrar para emplearlos como mulas para el tráfico de drogas así como para el lavado del oro extraído al nororiente venezolano y claro, también vinculados con la trata de personas en cuyo caso, las mujeres jóvenes eran prostituidas o esclavizadas, y aquellas personas cuya edad o condición no les permitía desempeñar estas actividades ilícitas, eran utilizadas para la venta de órganos.

También pudo verificarse que, entre la corriente migratoria proveniente de Venezuela, se encontraban ciudadanos de nacionalidad cubana y colombiana, especialmente en el proceso migratorio hacia los países del sur, tales como Ecuador, Perú, Chile, Brasil, Argentina, Uruguay; así como algunos ex presidiarios que fueron liberados en Venezuela argumentando falta de recursos para sostener a los detenidos y también para aliviar el hacinamiento carcelario de ese país.

En el mes de julio se realizó en México en la ciudad de Puebla una nueva reunión de los integrantes del Foro de Sao Paulo con el apoyo del partido político MORENA al que pertenece el Presidente Manuel López Obrador, bajo la denominación de "Grupo de Puebla" autodefinido como un foro político y académico integrado por representantes políticos del mundo, fundado el 12 de julio de 2019. De acuerdo a sus fundadores el objetivo particular es articular ideas, modelos productivos, programas de desarrollo y 
políticas de Estado de carácter progresista, se compone por presidentes, ex presidentes, referentes políticos y sociales dentro del movimiento socialista y por académicos de doce países de habla hispana. Al terminar la reunión, el Presidente de Venezuela Nicolás maduro, dijo sentirse muy satisfecho de la reunión y acotó que "los planes de Foro de Sao Paulo se estaban cumpliendo de acuerdo con lo previsto".

\section{La incursión en Ecuador del Foro de Sao Pulo}

En Ecuador entre el 03 y el 13 de octubre de 2019, las organizaciones del transporte, sociales aglutinadas en el Frente Unitario de Trabajadores (FUT) y Frente Popular (FP), organizaciones indígenas, partidarios de la Revolución Ciudadana, entre otros; realizaron movilizaciones a nivel nacional, con énfasis en la ciudad de Quito, para exigir se derogue las medidas económicas anunciadas por el Gobierno a través del Decreto Ejecutivo 883, en especial por el punto referido a la liberación del subsidio a los combustibles, protagonizando actos de violencia sin antecedentes en el país.

Los instrumentos de poder de la organización indígena, procuraron un efecto psicológico que se viralizó en redes sociales, donde por una parte se buscaba demostrar la valentía y comprometimiento indígena en la lucha social, como mecanismo para reivindicar sus pretensiones, creando las condiciones, con un discurso de inestabilidad; de lucha de clases y de reivindicaciones supuestamente legítimas pretendiendo justificar incluso la acción violenta y por otro lado deslegitimizar la represión realizada por los organismos de seguridad del Estado.

En cuanto al empleo de la tecnología en las protestas, se identificó el uso de medios de comunicación alternativos, redes sociales y troll center, cuyos perfiles tienen alta probabilidad de vínculos con Venezuela, así como de Europa (chalecos amarillos); medios que se utilizaron no solo para informar y manipular, sino también para generar el movimiento de los "zánganos" y donde las cuentas del Gobierno no tuvieron el impacto esperado.

Las manifestaciones produjeron heridos y fallecidos, saqueos, intentos de incursión a cinco instalaciones militares, daños a instalaciones públicas y privadas, afectaciones a 
sectores estratégicos; en una Asamblea que fue trasmitida en vivo por los medios de comunicación, Jaime Vargas presidente de la CONAIE hizo un llamado a los pueblos de la Amazonía a tomarse los pozos petroleros y que las FF.AA. retiren el respaldo al presidente, como medida de presión para exigir que se derogue Decreto 883.

Igualmente, la presencia de movimientos y organizaciones de izquierda, como el Foro de Sao Paulo y el Grupo de Puebla, brindaron el apoyo ideológico que busca la salida de Gobiernos que no son considerados progresistas. En cuanto a la presencia de grupos de choque que realizaron actos violentos, el Ministerio de Gobierno identificó en el mes de septiembre, un ingreso inusual de 250 cubanos con visa diplomática, que posteriormente se pudo comprobar s vinculación con el G-2 de Cuba (COIMC 2019).

Los insipientes grupos subversivos pueden estar conformados por integrantes de la FEUE, FESE, JRE, PCMLE, Juventud Guevarista, Vientos del Pueblo, Comuna, Latin King y CDRC; Asimismo, se ha establecido que estas organizaciones emplean modalidades descritas en manuales como el Mini Manual del Guerrillero, del Black Block y Antifa, para enfrentarse a las Fuerzas de Seguridad y generar a través de tácticas urbanas inestabilidad, zozobra e incertidumbre tanto en la población como en los elementos militares y/o policiales.

Militantes de la Juventud Revolucionaria del Ecuador, liderados por Ricardo Naranjo vicepresidente y estudiantes de los colegios Mejía, Montalvo y Montufar, participan de la marcha con artefactos explosivos (bombas incendiarias, molotov, voladores) los mismos que son lanzados a miembros de la Policía Nacional. Indígenas amazónicos (CONFENIAE) que arribaron a la ciudad de Quito para reforzar las movilizaciones, se emplearon tácticamente mediante la utilización de artefactos no convencionales registrados en manifestaciones indígenas como: escudos, detonación de artefactos explosivos caseros, entre otros.

De igual forma Inteligencia Militar pudo determinar la injerencia de ciudadanos venezolanos causando desmanes, y con pretensiones de realizar saqueos. Los actos violentos y vandálicos que se registraron en varias partes del país, dieron cuenta de saqueos 
a varios comercios, intentos de ingreso a urbanizaciones privadas, daño a los bienes públicos y privados, actos vandálicos por parte de manifestantes, provocando incendios en la Contraloría General del Estado, específicamente en los pisos 5 y 6 dónde se archivaban documentos probatorios de los actos de corrupción del gobierno anterior; incendio a medios de comunicación de oposición al correismo, provocando caos, temor y desabastecimiento, demostrando la incapacidad de los organismos de seguridad para atender todos los eventos denunciados a través del servicio de emergencias ECU-911.

En general, la movilización realizada por los diferentes grupos sociales podría resumirse desde el punto de vista estratégico militar como una "operación de insurgencia urbana y rural a través de una maniobra estratégica de líneas convergentes, movilizando, desplegando y concentrando fuerzas suficientes en el centro del país, especialmente en Quito, llevando como centro de gravedad al movimiento indígena y a los transportistas inicialmente para sembrar el caos y la incertidumbre con aliados estratégicos en las organizaciones políticas y sociales radicales y de izquierda con la infiltración y el apoyo de fuerzas irregulares guerrilleras disidentes de las FARC y de movimientos guerrilleros, con operaciones simultaneas a la paralización del estamento del estado en la toma de decisiones y de la economía del país con operaciones de terrorismo, sabotaje y subversión, apuntando a objetivos claves y estratégicos como son las funciones del Estado a través de la Asamblea nacional y su destrucción del edificio y vulneración de lo que significa; del ejecutivo hacia el Palacio de Gobierno de Carondelet, obligándolo a reaccionar en vez de accionar; de los medios de comunicación importantes del país, y sus periodistas, secuestrando a la sociedad ecuatoriana en sus casas sembrando el caos vandalismo y terror, combinando operaciones de guerra cibernética desde el exterior y desde el territorio nacional desinformando a la sociedad para aprovechar y crear un relato de un escenario inexistente con la finalidad de obedecer a una estrategia regional desde el grupo de Puebla y el Foro de Sao Paulo con el eje cubano chavista y de Nicaragua y recuperar el poder por asalto mediante la desestabilización del régimen establecido" (Cobo, F 2019).

En cuanto a los partidarios y afines al movimiento Revolución Ciudadana, participaron en la protesta a través de la activación de sus Comités para la Defensa de la 
Revolución Ciudadana (CDRC), estructura que se instaló en todo el territorio nacional en la década correísta y, donde se comprobó la participación y presencia de ciudadanos que fueron parte de pandillas como los "Latin King"; siendo generadores de violencia y acusados de haberse infiltrado en las manifestaciones.

En las manifestaciones que se desarrollaban en el Centro histórico se pudieron observar la participación de figuras políticas del Correismo, como: Gabriela Rivadeneira, Rodrigo Collaguazo, Virgilio Hernández y Paola Pavón, y otros vinculados posiblemente a grupos vandálicos y ciudadanos extranjeros entre estos: venezolanos y cubanos (COIMC, 2019). En este contexto Luis Saavedra, director de La Fundación Regional de Asesoría en Derechos Humanos (INREDH), manifestó que los excesos de la Policía y las FF.AA. ya han generado responsabilidad por violación de Derechos Humanos, a pesar de haber salido a enfrentar la situación sin armamento letal.

Cabe destacar la participación del Gobierno de México que brindó "protección y resguardo" a Luis Molina (Asambleísta Alterno), Soledad Buendía (Asambleísta Nacional), Edwin Jarrín (esposo Soledad Buendía), Carlos Viteri (Asambleísta Nacional), Tania Pauker (esposa Carlos Viteri), Leónidas Moreno (procurador síndico de la Prefectura de Pichincha) y Gabriela Rivadeneira, colaboradores del ex presidente Correa, quienes en rueda de prensa pidieron la renuncia al Presidente Moreno, determinándose la importancia de México para los gobiernos progresistas.

El impacto económico, según cálculos de los sectores industriales, del comercio y academia, bordean los 2200 millones de dólares, cifra que se acerca al 50\% de lo que se esperaba alcanzar con las medidas económicas propuestas, incidiendo en el financiamiento que el gobierno esperaba alcanzar.

De otro lado, se demostró la necesidad de depuración de la secretaría de Inteligencia en la cual más del $60 \%$ de analistas fueron contratados por el gobierno anterior, lo cual impide el flujo oportuno y el análisis imparcial de la información para producir inteligencia útil para la toma de decisiones. 
Mientras estaba por finalizar el levantamiento en Ecuador, se iniciaba en Perú y luego en Chile una jornada de protesta violenta que se mantiene hasta la fecha de elaboración del presente artículo, con inusitados niveles de violencia, mientras que Colombia se encuentra en condiciones similares de violencia, con un concepto estratégico similar al empleado en Ecuador.

En Bolivia, las manifestaciones provocadas por el fraude electoral de Evo Morales, provocaron su renuncia y su petición de asilo político en México

Mientras esto ocurría, el número dos del régimen venezolano Diosdado Cabello, manifestó su agrado por lo que calificó como "la brisa bolivariana que recorre la región" que se convertirá en un "huracán", y continuo: "lo que está pasando en Perú, Chile, Ecuador Argentina, Honduras es apenas la brisita, y viene un huracán bolivariano. Nosotros no estamos aislados en el mundo, por el contrario, Venezuela cada día está más consolidada" dijo Cabello durante un evento del partido socialista unido de Venezuela PSUV en el centro de Caracas (ABC de España)

Cabello reconoció estar contento de ver lo que está ocurriendo en América, “a mi si me alegra que los pueblos despierten" (Diario Las Américas 2019), mientras en Santiago de Chile ardían por la destrucción del Metro, la quema de un edificio de electricidad y el saqueo de los supermercados.

\section{La aplicación de la doctrina china de amenazas híbridas o la guerra sin límites}

Con estos antecedentes podemos colegir que existe relación entre la doctrina china de amenazas híbridas con la estrategia regional llevada a cabo desde Venezuela por el Foro de Sao Paulo pretendiendo imponer por cualquier medio su ideología e intereses en la región, si lo miramos detenidamente tenemos que:

Al movilizar las tropas venezolanas hacia la frontera con Colombia, se dio un indicio claro, de acuerdo a la doctrina de posibilidades de un eminente ataque, que con relación a la doctrina china de "guerra sin límites", equivaldría a una "casi guerra", con lo que se consiguió distraer la atención del gobierno colombiano y de la opinión internacional, 
mientras se realizaba una ofensiva de tipo político con el apoyo de Rusia y China quien a su vez distraía al gobierno norteamericano devaluando su moneda en $10 \%$ ante la subida de impuestos a las importaciones chinas por el mismo valor; desde Rusia se abría paralelamente un programa de opinión cuyos invitados eran miembros del Foro de Sao Paulo y desde donde se manejaba un troll center con abundante propaganda y desinformación empleando "fake news", denunciando corrupción gubernamental, atacando la imagen de los gobiernos ajenos a su ideología, burlándose de sus líderes y evidenciando la ineficiencia de sus instituciones, promoviendo además la intensificación de viejas enemistades tales como el regionalismo o los radicalismos por racismo o cualquier otra causa identificada de división interna de cada país, creando un clima propicio para la insurgencia y la violencia social.

Posteriormente y de manera casi coordinada incita a los levantamientos sociales en la región, infiltrando a personal del eje cubano, venezolano, ex subversivos y delincuentes, para que intensifiquen dichos levantamientos mediante la ejecución de actos vandálicos, ataques a infraestructura en instalaciones críticas y actos de terrorismo físico e informático, provocando la devaluación monetaria, impactos de riesgo país que devalúan las acciones del país atacado, y que generan una enorme cantidad de pérdidas y daños físicos que afectan gravemente a la gobernabilidad de los mismos. Dicha infiltración se caracteriza por la facilidad de evadir responsabilidades por parte del agresor, atemorizando a la población y generando caos de manera concertada y violenta, procurando situaciones de desconcierto en las que pueda negar el acceso a los servicios públicos y estratégicos, desorganizar y desunir a la población, denigrar y someter al régimen establecido para imponer por la fuerza un gobierno afín a su ideología que permita la materialización del paradigma marxista en la región

Afortunadamente la violencia generada está, contrariamente a lo planificado, generando un despertar de la sociedad civil que empieza a demostrar su rechazo a este tipo de actividades y empieza a oponerse a estos actos de violencia y cuyos resultados empiezan a dejarse ver en Bolivia, obligando a la renuncia de Evo Morales, en Colombia donde la población empieza a crear organizaciones contra el vandalismo y en Perú y Ecuador donde 
finalmente estos movimientos no lograron derrocar a los gobiernos legítimamente constituidos, a pesar de los daños económicos, sociales y morales ocasionados.

\section{Conclusiones}

Los hechos producidos en la región en este semestre, dejan en evidencia que se pretende volver a un régimen internacional bipolar o al menos se intenta buscando un escenario geográfico alejado de los generadores de la ideología como es América Latina

Las amenazas a la paz en la región, se muestran imbricadas a eventos ideológicos y delictivos trasnacionales y organizados que dificultan el análisis, desencadenan nuevamente problemas ideológicos y disturbios nacionales e internacionales, que se consideraban ya superados pero que dejan claro que la volatilidad de los agentes generadores del caos, no solo se mueven dentro de la variable física interconectada por la globalización, sino que además "juegan" con la temporalidad (uno de los elementos constitutivos de la narrativa de la sociedad líquida tiempo/espacio) de los acontecimientos resucitando temores y amenazas que aparentemente habían dejado de ser protagónicas

La presencia de quienes manejan los rezagos del comunismo en América Latina desde su posición más radical como es el caso de Cuba y Venezuela, ha quedado en evidencia en el desarrollo de las protestas recientes que se han tornado violentas en los diferentes países dela región. Las expresiones públicas de Diosdado Cabello en referencia a que "la brisa Bolivariana se tornará en un huracán que avanzará por la región” no dan lugar a dudar de la injerencia de estos gobiernos en la convulsión social que se ha desatado en la región.

Las características propias de la sociedad líquida, se reflejan en este tipo de amenazas en la que quienes la aplican, evaden responsabilidades y están dispuestos a cualquier actividad, lícita o no, convencional o no con tal de alcanzar sus objetivos que ya nos son solamente doblegar la voluntad de lucha del oponente, sino obligarlo a someterse a sus intereses. Por tanto, solo gracias a la construcción y promoción de herramientas de carácter multidisciplinario y participativo se podrán diseñar tácticas, técnicas y 
procedimientos que, frente a las amenazas híbridas, puedan contribuir a garantizar la paz, la estabilidad y el respeto al orden constitucional

Se vive una crisis hegemónica, en la que queda en evidencia que, no hay hegemones sino solo grandes potencias, esta ausencia de hegemones caracterizados no solo por su poderío bélico, sino más bien por su liderazgo y capacidad de disuasión motivacional, ha originado una desorientación sobre el paradigma neorrealista de los estados de la periferia, en este caso de América latina, en los que, ante la vertiginosidad de las mutaciones de las amenazas en cuanto a su capacidad de simbiosis y resiliencia pierden su capacidad anticipativa y libertad de acción operacional toda vez que la lentitud de adaptación del marco legal que norma sus actividades, impide la capacidad de reacción de los elementos que teóricamente materializan el uso legal de la fuerza por parte del Estado, e impiden la anticipación estratégica necesaria para detectar, neutralizar y eliminar temprana y oportunamente a las amenazas que se configuran en el ambiente postmoderno

La estrategia militar indica que se deben priorizar los medios cuando estos son escasos, en este caso inteligencia debe ser potenciada, depurada y adecuadamente articulada, tornándola dinámica y proactiva proveyéndole de un adecuado marco legal que la respalde y orientando claramente el esfuerzo de búsqueda, que permitan anticipar a las amenazas híbridas y reducir la incertidumbre, permitiendo así la toma adecuadas decisiones en el nivel estratégico

Las fuerzas militares y policiales deberán cooperar estrechamente y su éxito dependerá de su capacidad de adaptación y reacción para dar respuestas ágiles, omnicomprensivas y ordenadas a un sinnúmero de nuevos factores de inestabilidad, ya sean globales o locales, civiles o militares, colaborativos o conflictivos. Los conflictos y amenazas híbridas plantean la necesidad de adoptar líneas de análisis e investigación inter y transdisciplinarias, a través de las cuales se identifiquen y prioricen los campos específicos de acción y se promuevan soluciones innovadoras.

Luego de los desmanes ocasionados por la intervención socialista en la región, estos procurarán construir un relato ajeno a la realidad, hecho a la medida de los subversivos, que 
debe ser contrarrestado mediante información, comunicación y operaciones sicológicas reales. La apreciación y hermenéutica sesgada de los derechos humanos mediante diferentes actores, pretendiendo que los derechos de la minoría sean los que aparecen como vulnerados, desconociendo la vulneración de los derechos de la mayoría dan una clara muestra de la infiltración de los integrantes de esta ideología en los organismos de DDHH.

Los Estados perdieron la capacidad de disuasión mediante la justicia y deben recuperar la voluntad de lucha, la voluntad de emplear los medios para neutralizar este conflicto de alta intensidad donde está en juego en cada país el interés nacional y la libertad de la sociedad, pues se pretende implantar por la fuerza una ideología que no es la de la mayoría del pueblo latinoamericano.

\section{Referencias}

ABC de España. (2019). Diario digital del 22 de octubre.

Angarita-Calle, Carlos. (2008). Las relaciones económicas internacionales: un enfoque teórico. Bogotá, Colombia: Pap. Polit 13 (1).

Arenal, Celestina del. (1984). Introducción a las Relaciones Internacionales. Madrid: Tecnos.

Bárcena Alicia, Prado Antonio. (2015). Neoestructuralismo y corrientes heterodoxas en América latina y el Caribe a inicios del siglo XXI. Chile: CEPAL.

Bauman Zigmund. (2000). Modernidad Líquida. Paris: Editor digita: lestrobe.

Brown, Chris. (1997). International relations theory: New Normative Approaches. Nueva York: Columbia University Press.

Bustamante, Sabas. (2018). Relaciones internacionales cuaderno de trabajo. Disponible: http://w ww.researchgate.net/publication/323178246 .

Cobo, Fausto. (2019). Entrevista televisiva en Teleamazonas, octubre, Ecuador. 
COIMC. (2019). Comando Operativo de Inteligencia Militar Conjunta, Análisis de los disturbios de octubre del 2019. Quito, Ecuador (Reservado).

González Araceli. (2019). Clases magistrales en el Doctorado en RRII. Argentina: universidad Nacional de La Plata.

González. Araceli. (2017). Las Relaciones Internacionales: consideraciones disciplinarias, Argentina: Revista Relaciones Internacionales vol. 79, IRI, UNLP

Henríquez Federico. (1995). La globalización avanza hacia el pasado. Santo Domingo: Taller.

Krasner, Stephen. (2005) https://www.foreignaffairs.com/articles/2005-07-01/addressing$\underline{\text { state-failure }}$

Li, Cunshang (2008), Outline of chinese Traditional Philosophy. Beijing: Paths International Ltd,.

Llano, Alejandro. (1997). Tres formas de libertad. Navarra: Universidad de Navarra.

Matter, John y Hoffman Frank. (2005). The risk of Hibrid wars, US Army.

Mearsheimer, John. (2001). La tragedia de la política de las grandes potencias. Londres y Nueva York: W.W. Norton \& Company,

O.E.A. (2003). Declaración sobre Seguridad en Las Américas, México.

Stiglitz, Joseph. (2001). El Malestar de la Globalización. Madrid: Taurus.

Tello, Angel. (2010). La Teoría de las Relaciones Internacionales desde un punto de vista Político Polemológico. (Tesis Doctoral). Argentina: Universidad Nacional de la Plata.

Qiao, Liang y Wang Xiangsui. (1999). Unrestricted Warfare, Beijin: PLA Literature and Arts Publishing House.

Thomas, Scott. (2010). A globalized god. Foreing Affaire 89 (6).

Villegas, Crisálida. (2006). La investigación: Un Enfoque Integrador Transcomplejo. Venezuela: Universidad Bicentenaria de Aragua. 
Waltz, Kenneth. (1988). Teoría de la política internacional. Buenos Aires: ed. GEL.

Waltz, Kenneth. (2016). Teoría Internacional Política. México: Mc Graw Hill. 